\title{
Changes in the response properties of inferior colliculus neurons relating to tinnitus
}

\author{
Joel I. Berger ${ }^{* \dagger}$, Ben Coomber ${ }^{*}$, Tobias T. Wells, Mark N. Wallace and Alan R. Palmer
}

MRC Institute of Hearing Research, University Park, Nottingham, UK

Edited by:

Jinsheng Zhang, Wayne State

University, USA

\section{Reviewed by:}

Aasef G. Shaikh, Case Western

Reserve University, USA

Roland Schaette, University College

London, UK

Sarah H. Hayes, University at Buffalo, USA

\section{*Correspondence:}

Joel I. Berger and Ben Coomber, MRC Institute of Hearing Research, University Park, Science Road, Nottingham NG7 2RD, UK

e-mail: joel@ihr.mrc.ac.uk; ben@ihr.mrc.ac.uk

${ }^{\dagger}$ Joel I. Berger and Ben Coomber are joint first authors
Tinnitus is often identified in animal models by using the gap prepulse inhibition of acoustic startle. Impaired gap detection following acoustic over-exposure (AOE) is thought to be caused by tinnitus "filling in" the gap, thus, reducing its salience. This presumably involves altered perception, and could conceivably be caused by changes at the level of the neocortex, i.e., cortical reorganization. Alternatively, reduced gap detection ability might reflect poorer temporal processing in the brainstem, caused by AOE; in which case, impaired gap detection would not be a reliable indicator of tinnitus. We tested the latter hypothesis by examining gap detection in inferior colliculus (IC) neurons following AOE. Seven of nine unilaterally noise-exposed guinea pigs exhibited behavioral evidence of tinnitus. In these tinnitus animals, neural gap detection thresholds (GDTs) in the IC significantly increased in response to broadband noise stimuli, but not to pure tones or narrow-band noise. In addition, when IC neurons were sub-divided according to temporal response profile (onset vs. sustained firing patterns), we found a significant increase in the proportion of onsettype responses after AOE. Importantly, however, GDTs were still considerably shorter than gap durations commonly used in objective behavioral tests for tinnitus. These data indicate that the neural changes observed in the IC are insufficient to explain deficits in behavioral gap detection that are commonly attributed to tinnitus. The subtle changes in IC neuron response profiles following AOE warrant further investigation.

Keywords: acoustic over-exposure, auditory, behavior, electrophysiology, gap detection, response types, tinnitus, tinnitus animal model

\section{INTRODUCTION}

Tinnitus is a phantom sound percept that affects $10-15 \%$ of the populations of industrialized countries (1). Tinnitus has a wide range of etiologies, but the most common cause is exposure to excessively loud or persistent noise; ototoxic drugs can also trigger the onset of tinnitus [for a recent review, see Ref. (2)].

Early research into the underlying pathological mechanisms of tinnitus, using animal models, was hampered by the lack of an objective means of identifying tinnitus. However, the development of behavioral tests has allowed tinnitus research to advance rapidly (3-6). The most commonly used behavioral model - gap prepulse inhibition of acoustic startle (GPIAS) - relies on measuring an innate reflex response to a startling stimulus. Briefly, a loud sound evokes an acoustic startle reflex. When the startling sound is preceded by a gap in and otherwise continuous background noise, the magnitude of the startle response is reduced in size, a phenomenon known as prepulse inhibition [PPI; $(6,7)$ ]. The impairment of gap detection (and subsequent PPI deficits) observed following acoustic over-exposure (AOE) or salicylate administration is thought to be caused by tinnitus "filling in" the gap, thus, reducing its salience (7-13). Others have suggested that behavioral deficits may actually reflect a deficit in temporal processing associated with the AOE, rather than tinnitus per se $(9,14)$.

Psychophysical gap detection thresholds (GDTs) have previously been correlated with neural gap detection responses (15). As a result, if neural GDTs were increased beyond the duration of the gap used in the behavioral test, this would highlight the underlying neural basis of behavioral deficits. Clearly, if impaired gap detection is to be used as an indicator for behavioral evidence of tinnitus, it is important to establish whether gap detection performance in the brain is within normal limits after AOE, as measured in vivo in auditory neurons. While Walton et al. (16) found no differences in neural GDTs between mice carrying a deafness gene and normal-hearing controls - indicating that temporal processing was not affected in these genetically modified mice - Yin et al. (17) demonstrated neural GDT deficits in guinea pigs (GPs) with a high-frequency hearing loss following AOE. However, no study to date has attempted to quantify neural GDTs in animals with behavioral evidence of tinnitus.

Previous work has implicated the inferior colliculus (IC), a midbrain auditory structure, in contributing to the generation of this phantom percept following AOE (18-20). A number of changes have been demonstrated in the response properties of IC neurons that include increased spontaneous firing rates $(18,19)$, tonotopic reorganization [in some cases; (21); although less conclusively in others; (22)], and increased bursting activity $(8,18)$. Alterations in both GABAergic and glycinergic inhibitory neurotransmission have been shown in the IC [for a review, see Ref. (23)], providing a plausible mechanism by which functional changes - such as modified patterns of neuronal firing - might occur.

Here, we investigated whether behavioral gap detection deficits - commonly attributed to tinnitus - can be explained by 
impaired temporal processing in the IC. To this end, we measured neuronal GDTs in the IC of GPs exhibiting behavioral evidence of tinnitus following unilateral AOE, and compared these with AOE GPs without behavioral evidence of tinnitus and unexposed control GPs. Neuronal GDTs in the IC have previously been shown to be in good agreement with those seen behaviorally (24), most likely due to the IC being an almost obligatory relay for the convergence of ascending auditory information (25). Consequently, inferences into behavioral performance can be reliably made from neural GDTs recorded in this auditory structure. Ultimately, this will provide insight into the neural mechanisms behind behavioral gap detection deficits following AOE, which is essential for understanding the reliability of the tinnitus behavioral model.

\section{MATERIALS AND METHODS}

\section{ANIMALS}

All procedures were carried out in accordance with the European Communities Council Directive of 24 November 1986 (86/609/EEC) and with the approval of the Animal Welfare and Ethical Review Body at the University of Nottingham, UK. Experiments were conducted on 15 male and female pigmented GPs weighing 300-500 $\mathrm{g}$ at the onset of behavioral testing. GPs were bred in-house and group-housed on a 12:12 h light:dark cycle. Food and water were freely available.

\section{BEHAVIORAL MEASURE OF TINNITUS}

The behavioral method used to identify tinnitus in this study is based on a gap detection paradigm devised by Turner et al. (6) in which we measured flexion of the pinna, or the Preyer reflex (7). The magnitude of the Preyer reflex is calculated as pinna displacement under different acoustic conditions, and these measurements are used to quantify gap-induced PPI of the reflex. In animals experiencing tinnitus, $\mathrm{PPI}$ is compromised; hence, the paradigm allows objective identification of tinnitus. This method is described in detail elsewhere $(7,8)$.

\section{BASELINE BEHAVIORAL TESTING}

Baseline PPI of the Preyer reflex was measured in each GP over a 2 -week period (minimum of three and a maximum of six testing sessions). Startling stimuli [broadband noise (BBN) bursts of $20 \mathrm{~ms}$; rise/fall time of $1 \mathrm{~ms}$ ] and continuous background noise conditions [either BBN or $2 \mathrm{kHz}$ wide narrow-band noise (NBN) centered at $5,9,13$, or $17 \mathrm{kHz}$ ] were used, as described previously $(7,8)$. The gap used to elicit gap-induced PPI in the present study was $50 \mathrm{~ms}$ in duration, consistent with that used by others [e.g., Ref. $(6,12,13)]$. After 2 weeks of baseline data collection, the significance of PPI was calculated as described in Berger et al. (7). Briefly, baseline data were pooled and the differences between "no gap" and "gap" trials were tested for statistical significance using a Wilcoxon rank-sum test to a 95\% confidence rating for each GP at each background frequency. GPs that exhibited significant PPI in all background sound conditions were unilaterally exposed to loud noise $(n=9)$.

\section{ACOUSTIC OVER-EXPOSURE}

Guinea pigs were anesthetized with ketamine (Ketaset; $50 \mathrm{mg} \mathrm{kg}^{-1}$, i.p.; Fort Dodge Animal Health Ltd., Southampton, UK) and xylazine (Rompun; $10 \mathrm{mg} \mathrm{kg}^{-1}$, i.p.; Bayer PLC, Newbury, UK), supplemented with further administrations of a mixture of ketamine and xylazine, in a ratio of 15:2 (i.m.), throughout the procedure. A homeothermic heating pad (Harvard Apparatus Ltd., Edenbridge, UK) and a rectal probe were used to monitor core body temperature and maintain it at $38 \pm 0.5^{\circ} \mathrm{C}$. Auditory brainstem responses (ABRs) were recorded prior to, immediately after, and 8 weeks following AOE to determine hearing thresholds, in the same manner as described previously (8). GPs were placed inside a sound-attenuated booth and remained there for the duration of the ABR recording and AOE. Following the collection of pre-trauma ABR thresholds, GPs were exposed to NBN bursts (duration of $500 \mathrm{~ms}$ and inter stimulus interval of $200 \mathrm{~ms}$; center frequency $10 \mathrm{kHz}$; bandwidth $1 \mathrm{kHz}$ ), presented to the left ear only at $120 \mathrm{~dB}$ SPL, for $1 \mathrm{~h}$ via a $25 \mathrm{~mm}$ loud speaker (Peerless DX25, Tymphany, Hong Kong), connected to a $20 \mathrm{~mm}$ diameter polyethylene tube in order to form a seal around the ear and maintain a closed sound system. To minimize the risk of damage to the contralateral (right) ear, the right pinna was folded over and a polyethylene tube plugged with cotton wool was placed over the ear. ABRs recorded immediately after AOE confirmed that trauma occurred unilaterally. The AOE protocol was designed to minimize long-term hearing threshold shifts.

\section{BEHAVIORAL CLASSIFICATION OF TINNITUS}

We employed a commonly used classification for identifying behavioral evidence of tinnitus [e.g., Ref. $(8,10,26,27)]$. Baseline gap detection data were pooled across all sessions. These were compared to pooled data acquired 7-8 weeks after AOE. This timepoint was selected based on the assumption that tinnitus develops within $7-8$ weeks following $\operatorname{AOE}(6,13)$ and that hyperactivity becomes no longer dependent on cochlear input $\sim 6$ weeks after AOE $(19,20)$. PPI at the 7-8 week time-point was expressed as a ratio compared to baseline (before/after). Thus, a value of 1 indicated no change in PPI (relative to baseline), whereas a value $<1$ indicated a reduction in PPI, while a value $>1$ suggested that an improvement in PPI. Significant reductions in gap-induced PPI at any background frequency (compared to baseline) were identified using a two-way analysis of variance (ANOVA) with a Bonferroni post hoc test $(P<0.05)$. GPs that exhibited a significant reduction in gap-induced PPI at one or more background frequencies were categorized as "tinnitus" animals, while those that did not were categorized as "no tinnitus" animals.

\section{SURGERY FOR NEUROPHYSIOLOGY}

Following behavioral confirmation of tinnitus, GPs were anesthetized with urethane $\left(0.5 \mathrm{~g} \mathrm{~kg}^{-1}\right.$ in $20 \%$ solution, i.p.; Sigma, UK), ketamine ( $40 \mathrm{mg} \mathrm{kg}^{-1}$, i.p.), and xylazine $\left(8 \mathrm{mg} \mathrm{kg}^{-1}\right.$, i.p.), supplemented with further administrations of a mixture of ketamine and xylazine, in a ratio of 15:2 (i.m.), throughout the procedure to maintain areflexia. A single injection of atropine sulfate $\left(0.06 \mathrm{mg} \mathrm{kg}^{-1}\right.$, s.c. $)$ was administered to suppress bronchial secretions. ABRs were then recorded to determine whether any permanent hearing threshold deficits were present. Following $\mathrm{ABR}$ recordings, GPs were tracheotomized and respired with $100 \%$ oxygen to maintain normal end-tidal $\mathrm{CO}_{2}$ partial pressure within a range of $28-38 \mathrm{mmHg}$. Core body temperature was 
monitored throughout, as described in the previous section. Animals were held in place using a stereotaxic frame, with hollow plastic speculae inserted into the ear canals replacing the ear bars. Throughout the duration of recording, animals remained inside a sound-attenuating chamber. Polyethylene cannulae $(>10 \mathrm{~cm}$ length, $0.5 \mathrm{~mm}$ outer diameter) were inserted into the bullae on each side, in order to equalize pressure across the tympanic membrane while maintaining closed-field stimulation conditions. The posterior fossa was opened to reduce respiratory pulsations of the brain. Craniotomies were performed over the right and left IC ( $\sim 4 \mathrm{~mm}$ diameter) using coordinates described in the guinea pig atlas of Rapisarda and Bacchelli (28). The Dura mater was excised and pairs of electrode arrays were slowly lowered into the brain at $10^{\circ}$ to the vertical plane in the medial-lateral orientation. This was not only required to accommodate electrode arrays simultaneously on the two sides but also enabled a perpendicular approach to the isofrequency laminae of the IC (29). The exposed cortex was kept moist with intermittent application of warm $0.9 \%$ sodium chloride solution. When necessary, the brain surface was covered in $1.5 \%$ agar for stabilization during recording.

\section{SINGLE-UNIT RECORDING}

To simultaneously record from left and right IC, two arrays of four glass-coated tungsten electrodes $(\sim 1-3 \mathrm{M} \Omega$ impedance) were attached to separate circuit boards (30). The tips of the electrodes were aligned and separated by $\sim 200 \mu \mathrm{m}$. These electrode arrays were connected to a Tucker Davis Technologies (TDT) System 3 via TDT headstage amplifier and a TDT Medusa preamplifier. Electrodes were advanced into left and right IC, and extracellular single-units were recorded (filtered between $600 \mathrm{~Hz}$ and $3 \mathrm{kHz}$ ). Data were collected using Brainware (software developed by J. Schnupp, University of Oxford, UK).

\section{AUDITORY STIMULI AND RECORDING PROCEDURE}

Etymotic ER-4 earphones (Etymotic Research, Inc., IL, USA) were inserted into the hollow speculae, in order to present auditory stimuli diotically and create sealed acoustic systems. Search stimuli, generated using the TDT System 3, consisted of a wideband noise (duration $50 \mathrm{~ms}$ ), with cosine-squared ramps lasting $8 \mathrm{~ms}$ and a repetition interval of $300 \mathrm{~ms}$. Following online isolation of a single-unit, a frequency-response area was measured by presenting pure tone bursts ( $50 \mathrm{~ms}$ duration; $200 \mathrm{~ms}$ repetition interval) over a range of frequencies $(50 \mathrm{~Hz}$ to $\sim 25 \mathrm{kHz}$ randomly interleaved at 0.25 octave intervals) and sound levels (attenuations of $0-95 \mathrm{~dB}$ in $5 \mathrm{~dB}$ steps, from a maximum of $\sim 100 \mathrm{~dB}$ SPL). This enabled determination of the characteristic frequency (CF) of isolated single-units across multiple electrodes, which could potentially have disparate CFs.

\section{NEURAL GAP DETECTION THRESHOLDS}

The minimum gap detection threshold (MGDT) was measured for each isolated single-unit in GPs with behaviorally identified tinnitus $(n=7)$, AOE GPs without tinnitus $(n=2)$ and in an additional group of control animals $(n=6)$ that were not noiseexposed. Auditory stimuli comprised a noise/tone burst (duration of $200 \mathrm{~ms}$, on/off ramps of $0.5 \mathrm{~ms}$ ), followed by a fixed-length period of silence or "gap" (durations of either 1, 2, 4, 8, 10, 20, 50 or $75 \mathrm{~ms}$ ), and a final noise/tone burst (duration of $50 \mathrm{~ms}$, on/off ramps of $2 \mathrm{~ms}$ ). Each gap condition was presented in ascending order (20 repetitions, $700 \mathrm{~ms}$ repetition interval), for three types of carrier: (i) BBN, (ii) NBN (matched to the behavioral NBN background sound conditions, i.e., 4-6, 8-10, 12-14, or 16-18 kHz), or (iii) pure tones. Pure tones were presented at a frequency that matched the CF of each single-unit, as determined by frequencyresponse areas. NBN bursts were presented at the frequency range closest to the CF of a given neuron. In all cases, pre-gap and postgap stimuli were spectrally identical, and were presented at the same sound level.

The sound level was determined based on that used in the behavioral test: as described in our previous work, we determined optimal sound levels of startling stimuli $(95,100$, or $105 \mathrm{~dB}$ SPL) and background carrier $(55,60$, or $70 \mathrm{~dB}$ SPL $)$ to maximize baseline PPI for each animal [sound level-dependency test; see Ref. (7)]. In order to better compare behavioral performance and neural MGDTs (determined electrophysiologically), we selected analogous sound levels for both approaches. Although these were not directly comparable owing to a number of methodological differences (e.g., speaker type and anesthesia), this was deemed the most consistent way of selecting an appropriate sound level for MGDT measurement.

\section{DATA ANALYSIS FOR MGDTs}

Minimum gap detection thresholds of single-units were defined as the minimum gap duration where a significant increase in firing ( $>2 \mathrm{SD}$ above the mean firing rate within the preceding $50 \mathrm{~ms}$ ) could be detected following the onset of the post-gap stimulus, i.e., a comparison of firing immediately after the gap vs. during or before the gap. These responses were further required to contain a minimum of three spikes (collected over 20 sweeps). MGDTs were assessed using custom-written Matlab software (R2009b, MathWorks, MA, USA). In addition, post-stimulus time histogram (PSTH) plots for each cell were visually inspected for confirmation purposes.

Single-unit MGDTs were calculated for each sound condition: pure tones (at CF), BBN, and NBN. For the NBN condition, singleunits were included if the CF of a given single-unit was $\leq 1 \mathrm{kHz}$ from the lower or upper limits of an NBN frequency range, e.g., single-units with a CF of 3-7 kHz were assessed in response to 4 $6 \mathrm{kHz}$ NBN stimuli. This was done to restrict the effect that having a NBN frequency substantially different from the CF may have on MGDTs. A small subset of units exhibited offset responses only, i.e., neuronal firing was suppressed during the presentation of auditory stimuli. For these single-units, MGDTs were determined solely by visual inspection, using a discernible increase in firing following the offset of the gap as an indication that the gap was detected.

The number of responsive neurons to each gap condition was expressed as a percentage of all recorded neurons in tinnitus and control groups. Mean MGDTs were also compared for tinnitus, no tinnitus, and control GPs for each noise condition, and differences between the three experimental groups statistically assessed with a Kruskal-Wallis test with a Dunn's post hoc test. Data were initially pooled regardless of the side from which they were recorded, as we have previously demonstrated that a unilateral noise exposure resulted in bilateral increases in spontaneous firing rates (8) and 
this method of analysis preserved larger sample sizes. Analysis of MGDTs across left (ipsilateral) and right (contralateral) IC is further supported by the fact that the behavioral task involves binaural presentation of stimuli. However, MGDT data were subsequently analyzed independently for each side, as the unilateral AOE may have feasibly resulted in differences between sides. Statistical comparisons were made with a two-way ANOVA and Tukey's HSD post hoc test.

\section{RESPONSE PROPERTIES OF IC NEURONS}

Inferior colliculus single-units were sub-divided according to response profiles exhibited to gap detection stimuli. Three different classes were extracted from these data: (i) if a single-unit responded to the onset of the first $200 \mathrm{~ms}$ stimulus, but ceased firing within $\sim 30 \mathrm{~ms}$, it was labeled as an onset response; (ii) if a single-unit showed a response that lasted more than $30 \mathrm{~ms}$ of the first $200 \mathrm{~ms}$ stimulus, it was designated as a sustained response; (iii) single-units that were predominantly silent throughout the presentation of both the initial $200 \mathrm{~ms}$ stimulus and the second $50 \mathrm{~ms}$ stimulus, yet responded following the offset of either stimulus, were categorized as exhibiting an offset response. The classifications for onset and sustained-response single-units were based on the scheme of Astl et al. (31), while offset responses were classified in a similar manner to Kasai et al. (32).

The proportion of response types was calculated for control, no tinnitus, and tinnitus groups, and compared. Chi-squared tests were used to determine whether there were any significant differences in the distributions of response types overall or when sub-divided according to side. MGDT data were also subdivided, according to response profile (and experimental group) and statistically assessed with a two-way ANOVA.

\section{RESULTS}

Nine GPs were noise-exposed and tested for behavioral evidence of tinnitus 7-8 weeks following AOE. A further six animals were used solely for neurophysiological recordings, in order to serve as a control group (i.e., no noise exposure). An example of behavioral gap detection deficits in a tinnitus GP is shown in Figure 1A. Seven of the nine noise-exposed GPs exhibited behavioral evidence of tinnitus. This equates to $\sim 75 \%$ of animals developing tinnitus, which is consistent with data from our previous study using the same AOE paradigm and behavioral criteria (8). Across animals, 4-6 kHz was the most common background sound frequency at which significant gap detection deficits were found, although some GPs showed a significant decrease in behavioral gap detection at multiple frequencies following AOE (Figure 1).

Linear regression analysis comparing ABR threshold shift with change in PPI (for each background frequency) was used to determine whether the behavioral gap detection deficits could simply be a result of hearing loss caused by AOE, i.e., whether tinnituslike behavior worsened with increasing hearing threshold shifts. There was no significant correlation between ABR threshold shifts and PPI deficits $(r=0.05 ; P=0.18)$, suggesting that the behavioral gap detection deficits observed here were not simply a result of reduced hearing thresholds (Figure 1C).

In our data, behavioral gap detection deficits were not restricted to the noise exposure frequency. This is in contrast with previous

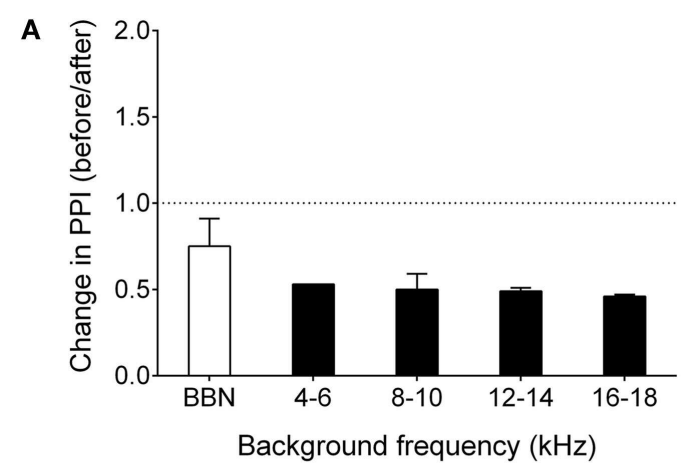

B
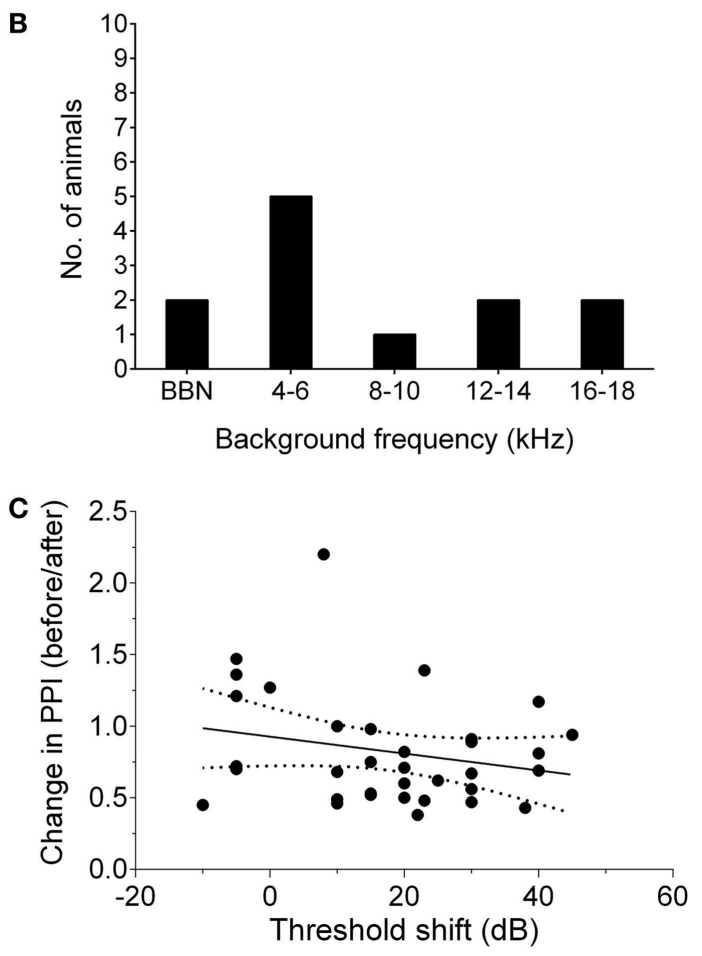

FIGURE 1 | Behavioral signs of tinnitus. (A) Behavioral performance after AOE is shown for a representative "tinnitus" animal, expressed as change in PPI, i.e., a ratio of performance before vs. after noise exposure, at each background frequency. Values $<1$ indicate poorer gap detection, while a value close to 1 indicates no effect of noise exposure. Black bars indicate frequencies with significantly worse gap detection $(P<0.05)$. (B) The number of animals exhibiting gap detection deficits at each background frequency. Note: some animals exhibited gap detection deficits at more than one frequency. (C) There was no significant correlation between behavioral performance and ABR threshold shifts. Solid line indicated linear regression. Dotted lines show 95\% confidence intervals. Each point represents the behavioral performance for a given background condition in a single animal, relative to the $A B R$ threshold shift at the corresponding frequency.

animal studies using the gap detection method, e.g., in mice (11) and gerbils (33). The variability in tinnitus frequency in the present study can, to some extent, be explained by the noise exposure paradigm. Despite using NBN exposure, broadband shifts in ABR thresholds on the exposed side were observed (18.57 dB HL, \pm 6.14 for $5 \mathrm{kHz}, 16.43 \mathrm{~dB} \mathrm{HL}, \pm 4.72$ for $10 \mathrm{kHz}$, and $18.57 \mathrm{~dB} \mathrm{HL}, \pm 6.96$ 


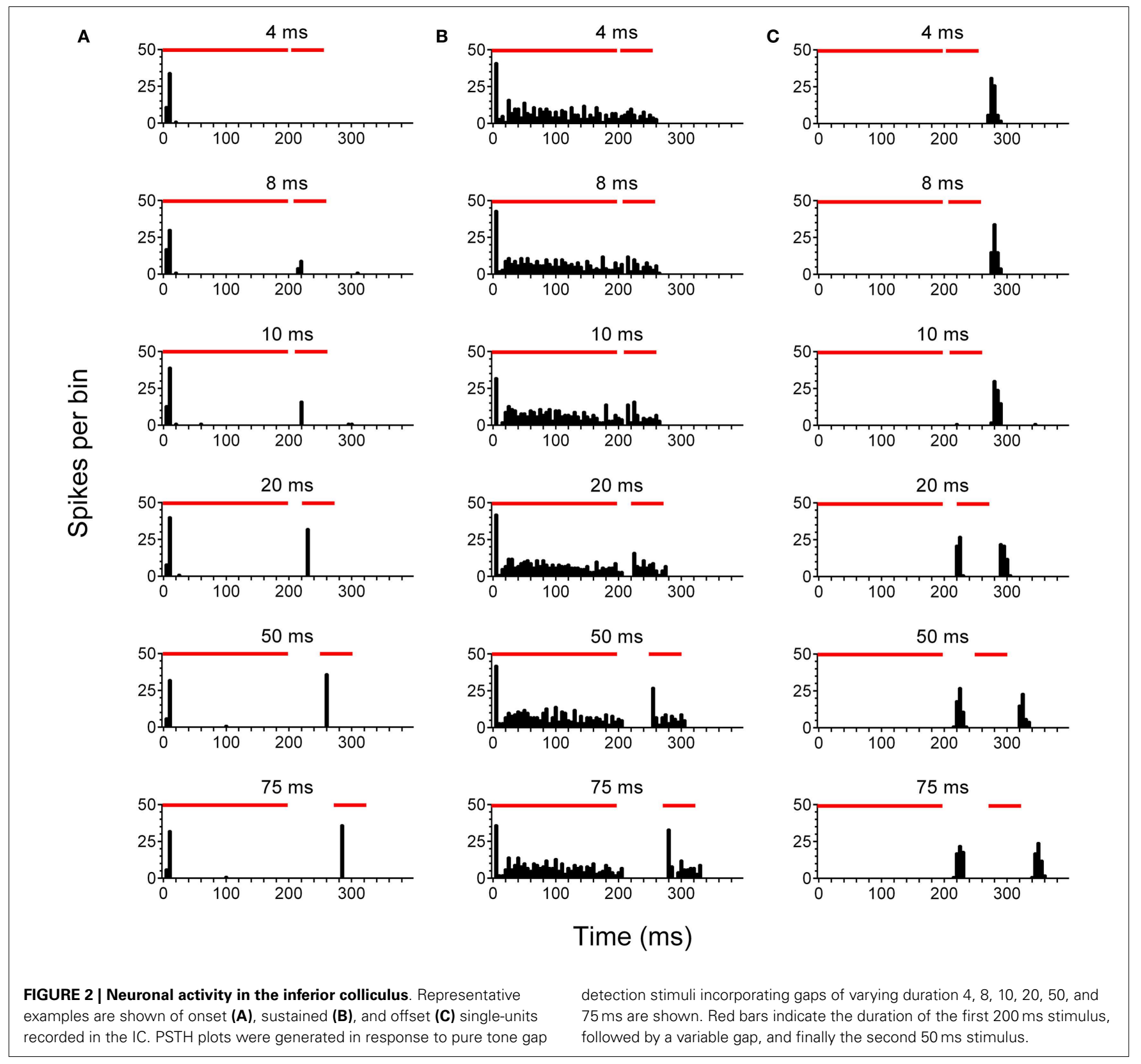

for $15 \mathrm{kHz}$ ), which is consistent with our previous data (8). This is in keeping with the findings of some other groups $(9,34)$. Therefore, given that the immediate effects were broadband, any damage that resulted in tinnitus may not have been restricted to one particular frequency. Behavioral deficits not restricted to the noise exposure frequency have also been demonstrated previously in rats $(34,35)$, and Engineer et al. (36) demonstrated behavioral deficits centered below the noise exposure frequency. Moreover, human studies have demonstrated considerable variability in frequency estimates of tinnitus (37-40).

\section{CHANGES IN IC SINGLE-UNIT RESPONSE TYPES FOLLOWING AOE}

After concluding behavioral testing, single-unit recordings were performed in the left, ipsilateral IC $\left(\mathrm{IC}_{\mathrm{ipsi}}\right)$ and right, contralateral
IC ( $\left.\mathrm{IC}_{\text {contra }}\right)$ of control ( $n=88$ cells), no tinnitus ( $n=42$ cells), and tinnitus ( $n=105$ cells) groups of GPs. Figure 2 highlights the three categories under which IC units were classified, and also shows responses to pure tone stimuli with varying gap lengths, as used for determining MGDTs: Figure 2A shows a representative example of a cell responding to the stimulus onset; Figure 2B shows a cell exhibiting a sustained response; Figure 2C shows a cell responding only to the offset of a stimulus. Data from no tinnitus, tinnitus, and control groups were analyzed to determine whether there were any changes in proportions of the types of responses exhibited by IC neurons. The percentage of "onset" and "sustained" single-unit types in response to pure tone stimuli for each group are shown in Figure 3A. 
In controls, $26 \%$ of cells exhibited onset responses $(n=23)$, $68 \%$ were of a sustained type $(n=60)$, and $6 \%$ displayed offset responses $(n=5)$. In tinnitus animals, $51 \%$ of units were onset-responders $(n=54)$, while $48 \%$ of units were classified as sustained responses $(n=50)$, and only $1 \%$ of units demonstrated offset responses $(n=1)$. In no tinnitus animals, $62 \%$ of units were onset-responders $(n=26)$, while $38 \%$ of units were classified as sustained responses $(n=16)$. Chi-squared tests were applied to compare the frequency with which different types of units occurred (excluding offset responses due to the extremely low incidence), this revealed that tinnitus GPs - proportionally exhibited significantly fewer sustained responses than controls and significantly more onset responses $\left[\chi^{2}(1)=29.52, P<0.0001\right]$. When comparing no tinnitus GPs to controls, there were again significantly fewer sustained responses and significantly more onset responses $\left[\chi^{2}(1)=23.95, P<0.0001\right]$. There was no significant difference between no tinnitus and tinnitus GPs in response types $\left[\chi^{2}(1)=1.65, P=0.20\right]$. However, as Figure 3B highlights, overall there were considerably fewer recorded units in no tinnitus GPs (compared to the other two groups) meaning that the sample size was not large enough to determine whether changes in this group were reliable or a result of a sampling bias.

In order to determine whether the change in the proportion of response types between control, no tinnitus, and tinnitus groups was limited to a specific side, data were analyzed for $\mathrm{IC}_{\mathrm{ipsi}}$ and $\mathrm{IC}_{\text {contra }}$ separately (Figure 3C). Offset units were again excluded from analysis due to their low incidence ( $n=6$ across all experimental groups). In control animals, there was no significant difference between the two sides: $27 \%$ of units recorded from the $\mathrm{IC}_{\mathrm{ipsi}}$ exhibited onset responses $(n=15)$ and $73 \%$ exhibited sustained responses $(n=41)$, compared with $30 \%$ onset $(n=8)$, and $70 \%$ sustained $(n=19)$ from the $\mathrm{IC}_{\text {contra }}\left[\chi^{2}(1)=0.10\right.$, $P=0.76]$. In tinnitus animals, separating data according to side clearly highlighted where response-type differences between the two experimental groups occurred: the proportions of response types recorded from the $\mathrm{IC}_{\mathrm{ipsi}}$ were similar to controls; $27 \%$ onset responses $(n=8)$ and $73 \%$ sustained responses $(n=22)$. However, in the $\mathrm{IC}_{\text {contra }}$ of tinnitus GPs, $62 \%$ of units exhibited onset responses $(n=46)$, compared with only $38 \%$ sustained responses $(n=28)$. The difference in the proportion of onset vs. sustained response types between $\mathrm{IC}_{\mathrm{ipsi}}$ and $\mathrm{IC}_{\text {contra }}$ in tinnitus GPs was highly significant $\left[\chi^{2}(1)=46.42, P<0.0001\right]$. In no tinnitus GPs, the change in the proportion of onset types was evident for both the $\mathrm{IC}_{\mathrm{ipsi}}$ and the $\mathrm{IC}_{\text {contra }}$, and there was no significant difference between the two sides: $67 \%$ of units recorded from the $\mathrm{IC}_{\mathrm{ipsi}}$ exhibited onset responses $(n=22)$ and $33 \%$ exhibited sustained responses $(n=11)$, compared with $44 \%$ onset $(n=4)$, and $56 \%$ sustained $(n=5)$ from the $\mathrm{IC}_{\text {contra }}\left[\chi^{2}(1)=2.07, P=0.15\right]$. It should be noted, however, that the sample sizes in the $\mathrm{IC}_{\text {contra }}$ in this group were very small when separated in this manner.

In summary, AOE resulted in a marked shift in IC single-unit response types, i.e., a significantly higher proportion of units classified as onset-responders, compared with controls. In tinnitus animals, this shift was only found in the $\mathrm{IC}_{\text {contra }}$, which - taken alone - is perhaps not altogether surprising given the unilateral nature of the AOE paradigm. In no tinnitus animals, this shift was evident to a greater degree in $\mathrm{IC}_{\mathrm{ipsi}}$ compared with $\mathrm{IC}_{\text {contra }}$,
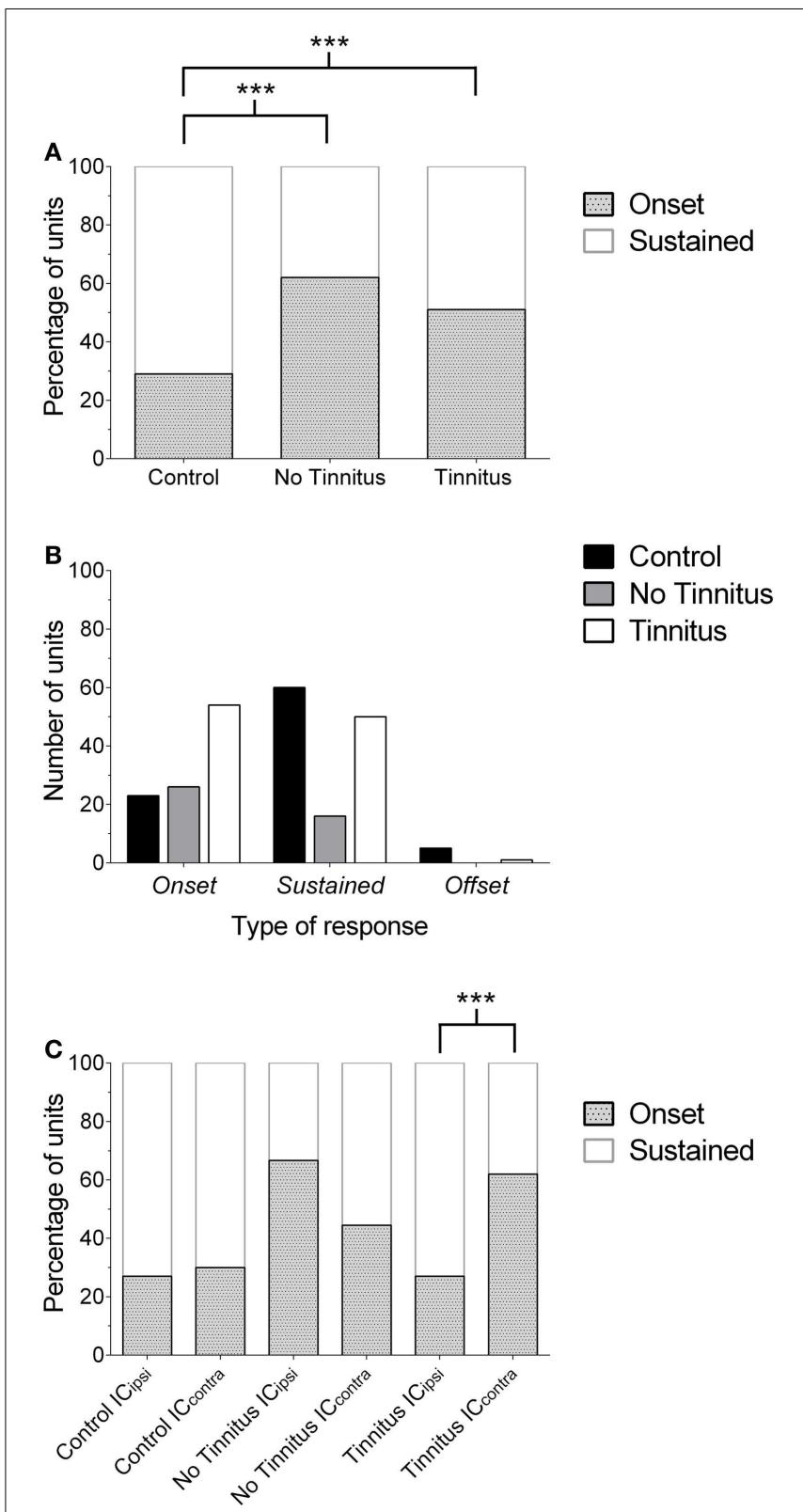

FIGURE 3 | Changes in the proportion of IC response profiles. (A) The proportion of single-units exhibiting either an onset or sustained-response profile is shown for each experimental group. Offset units have been excluded from this graph for the purposes of clarity (due to their low incidence). Onset responses significantly increased (relative to sustained units) in no tinnitus and tinnitus animals, compared with controls (***P<0.0001). (B) Number of units recorded for each experimental group, separated according to response-type classification. The number of units recorded in no tinnitus GPs was considerably lower than controls and tinnitus GPs. (C) The increase in the proportion of onset units in tinnitus GPS was isolated to the contralateral (relative to AOE) IC (***P<0.0001). In no tinnitus GPs, this increase was present in both the $I_{\text {ipsi }}$ and the $I C_{\text {contra }}$.

although there was no significant difference between the two sides. The mechanisms underlying the difference in the laterality of effects between no tinnitus and tinnitus GPs are unclear, and are difficult to resolve with the present data. 

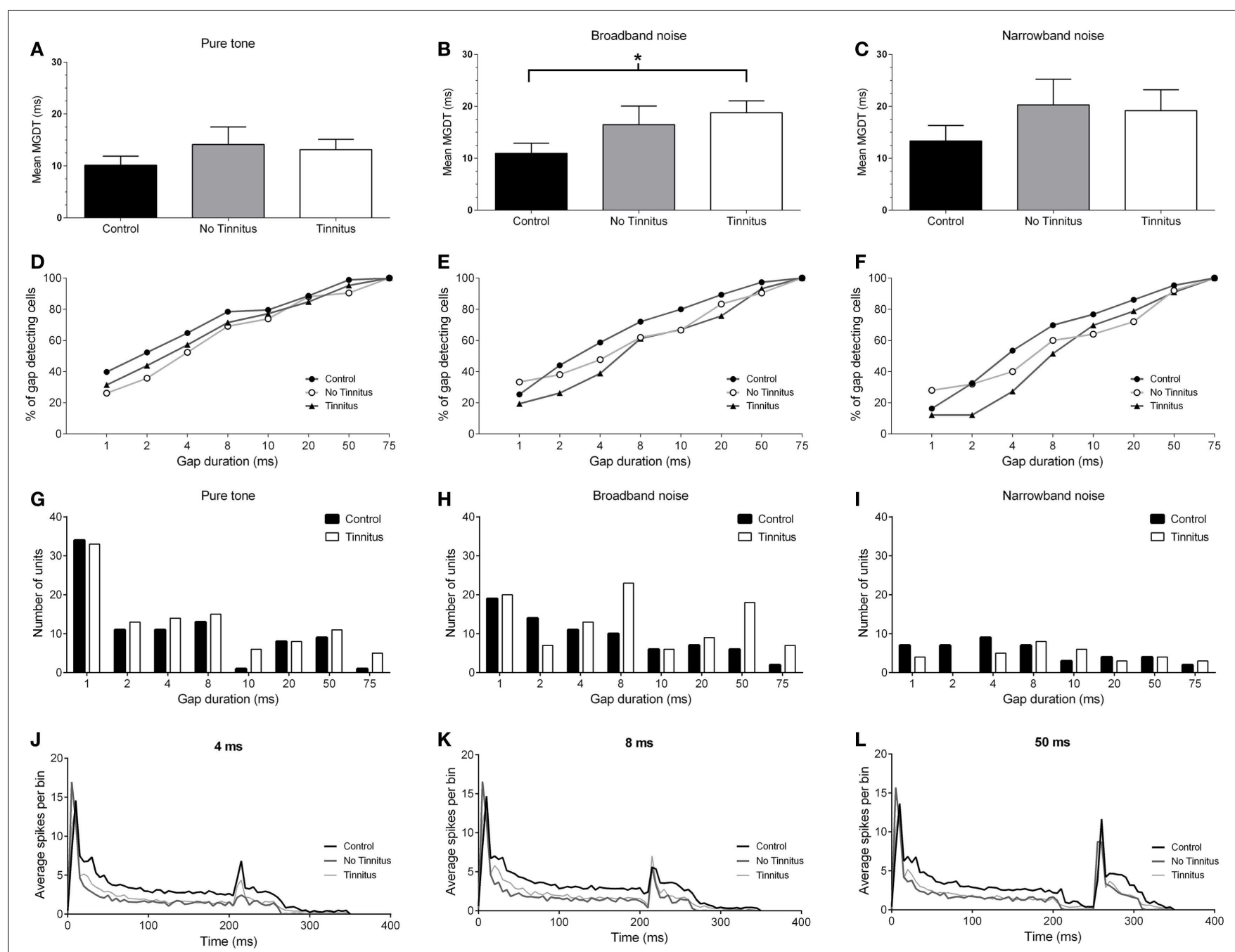

FIGURE 4 | Neural gap detection in the IC. (A) Mean MGDTs in response to pure tone stimuli at CF for control $(n=96)$, no tinnitus $(n=42)$, and tinnitus ( $n=109$ ) animals. (B) Mean MGDTs in response to BBN for control ( $n=76)$, no tinnitus $(n=42)$, and tinnitus $(n=103)$ groups $\left({ }^{*} P<0.05\right)$. (C) Mean MGDTs in response to NBN for control $(n=43)$, no tinnitus $(n=25)$, and tinnitus ( $n=33$ ) GPs. (D) The percentage of gap-detecting cells, relative to total cell count in response to pure tone stimuli for control, no tinnitus, and tinnitus GPs. For each gap duration $(1,2,4,8,10,20,50$, and $75 \mathrm{~ms})$ the percentage of cells able to detect a gap less than or equal to a given duration is shown. (E) The percentage of gap-detecting cells with a BBN carrier. (F) The percentage of gap-detecting cells with an NBN carrier. (G) Distribution of the number of units with MGDTs for each gap duration in response to pure tone stimuli, shown for control and tinnitus GPs. For the purposes of clarity, no tinnitus GPs have been omitted. (H) Distribution of MGDTs in response to BBN stimuli. (I) Distribution of MGDTs in response to NBN stimuli. (J) The averaged population responses of IC neurons in control (black line), no tinnitus (dark gray line), and tinnitus (light gray line) groups for gaps of $4 \mathrm{~ms}$ duration, in response to a pure tone carrier. (K) Averaged population responses to gaps of $8 \mathrm{~ms}$ duration. (L) Averaged population responses to gaps of $50 \mathrm{~ms}$ duration.

\section{NEURAL GAP DETECTION THRESHOLDS WITH PURE TONE STIMULI}

The mean $( \pm$ SEM) MGDTs for pure tone stimuli, separated according to experimental group, are shown in Figure 4A. MGDTs were $10.22 \mathrm{~ms}( \pm 1.75 \mathrm{~ms} ; n=88)$ for controls, $14.12 \mathrm{~ms}$ $( \pm 3.39 \mathrm{~ms} ; n=42)$ for no tinnitus GPs, and $13.14 \mathrm{~ms}( \pm 1.97 \mathrm{~ms}$; $n=105)$ for tinnitus GPs; no statistically significant differences were found between the three groups $(P=0.09)$. Pure tone MGDTs were also plotted as a percentage of the total number of cells responding to each gap duration tested in Figure 4D. In control GPs, 99\% of single-units exhibited MGDTs of $50 \mathrm{~ms}$ or less, while in no tinnitus GPs, MGDTs of $50 \mathrm{~ms}$ or less were observed in $90 \%$ of cells and in tinnitus
GPs, MGDTs of $50 \mathrm{~ms}$ or less were observed in $95 \%$ of cells recorded.

\section{NEURAL GAP DETECTION IN RESPONSE TO A BBN STIMULUS}

Figure 4B shows the mean MGDTs, and Figure 4E shows the percentage of gap-detecting cells for each group in response to BBN. Mean ( \pm SEM) MGDTs in response to BBN were $10.95 \mathrm{~ms}$ $( \pm 1.97 \mathrm{~ms} ; n=75)$ for controls, $16.48 \mathrm{~ms}( \pm 3.58 \mathrm{~ms} ; n=42)$ for no tinnitus GPs, and $18.79 \mathrm{~ms}( \pm 2.27 \mathrm{~ms} ; n=103)$ for tinnitus GPs. MGDTs were significantly longer for tinnitus GPs compared with controls $(P<0.05)$, but not when compared with no tinnitus GPs. However, importantly, the percentage of units with MGDTs 
of $50 \mathrm{~ms}$ or less were similar for control (97\%), no tinnitus (92\%), and tinnitus GPs (93\%). The sample size for responses to BBN and NBN stimuli was smaller than for pure tones, as in some cases cells either did not respond to these stimuli, or exhibited a $\mathrm{CF}>1 \mathrm{kHz}$ from the NBN frequency range.

\section{GAP DETECTION IN RESPONSE TO NBN STIMULI}

Figure 4C shows the mean MGDTs for NBN, while the percentage of gap-detecting cells are shown in Figure 4F. Mean $( \pm S E M)$ MGDTs were $13.33 \mathrm{~ms}( \pm 3.64 \mathrm{~ms} ; n=43)$ for controls, $20.28 \mathrm{~ms}$ $( \pm 4.96 \mathrm{~ms} ; n=25)$ for no tinnitus GPs, and $19.18 \mathrm{~ms}( \pm 4.03 \mathrm{~ms}$; $n=33$ ) for tinnitus GPs. No significant differences were evident between the three groups $(P=0.18)$ and, once again, the percentage of units with MGDTs $\leq 50$ ms were similar for control (95\%), no tinnitus (92\%), and tinnitus (91\%) groups.

To summarize, although MGDTs were significantly increased in tinnitus GPs in response to BBN stimuli, the effects on the percentage of cells capable of detecting gaps of $\leq 50 \mathrm{~ms}$ were negligible, regardless of the characteristics of the stimulus or the experimental group. A lack of dramatic change in neural gap detection in tinnitus GPs is further highlighted by Figures 4G-I, which show the number of units with MGDTs at each gap duration in response to the three different stimulus conditions. For the purposes of clarity, no tinnitus GPs have been omitted from these histograms. These figures clearly demonstrate that many units responded to gaps of short durations, regardless of whether they were recorded from tinnitus GPs or not.

\section{POPULATION RESPONSES TO GAPS}

Figures 4J-L show the averaged population responses for each experimental group to gaps with durations of 4,8 , and $50 \mathrm{~ms}$, respectively, using a pure tone carrier. Although the response to the second stimulus onset was weaker in tinnitus GPs for the $4 \mathrm{~ms}$ gap condition (Figure 4J) - indicating slightly poorer gap detection - the response to the second stimulus with an $8 \mathrm{~ms}$ gap in tinnitus GPs actually slightly exceeded that of control GPs (Figure 4K), and control and tinnitus GPs were equivalent when a $50 \mathrm{~ms}$ gap was presented (Figure 4L). This further highlights that, while some minor differences were evident for short-gap durations, the detectability of gaps $\geq 8 \mathrm{~ms}$ was similar for controls and tinnitus GPs. For no tinnitus GPs, responses to $4 \mathrm{~ms}$ gaps were clearly reduced compared to both control GPs and tinnitus GPs. For gaps $\geq 8$ ms duration, responses were similar to those of controls. The apparent reduction in sustained firing (following the onset response) in tinnitus and no tinnitus GPs was most likely a result of the proportional reduction in sustained single-unit responses in these groups.

\section{LATERALITY IN NEURAL GAP DETECTION}

Due to the unilateral nature of the AOE protocol, it was entirely plausible that any changes in MGDTs may have been restricted solely to the $\mathrm{IC}_{\text {contra }}$. Thus, pooling data from both sides may have diluted any AOE-related changes in MGDTs. Consequently, MGDTs in response to pure tones and BBN were sub-divided according to recording side, for control, no tinnitus, and tinnitus GPs (Figures 5 and 6). This was not feasible for NBN data owing to the small sample size.

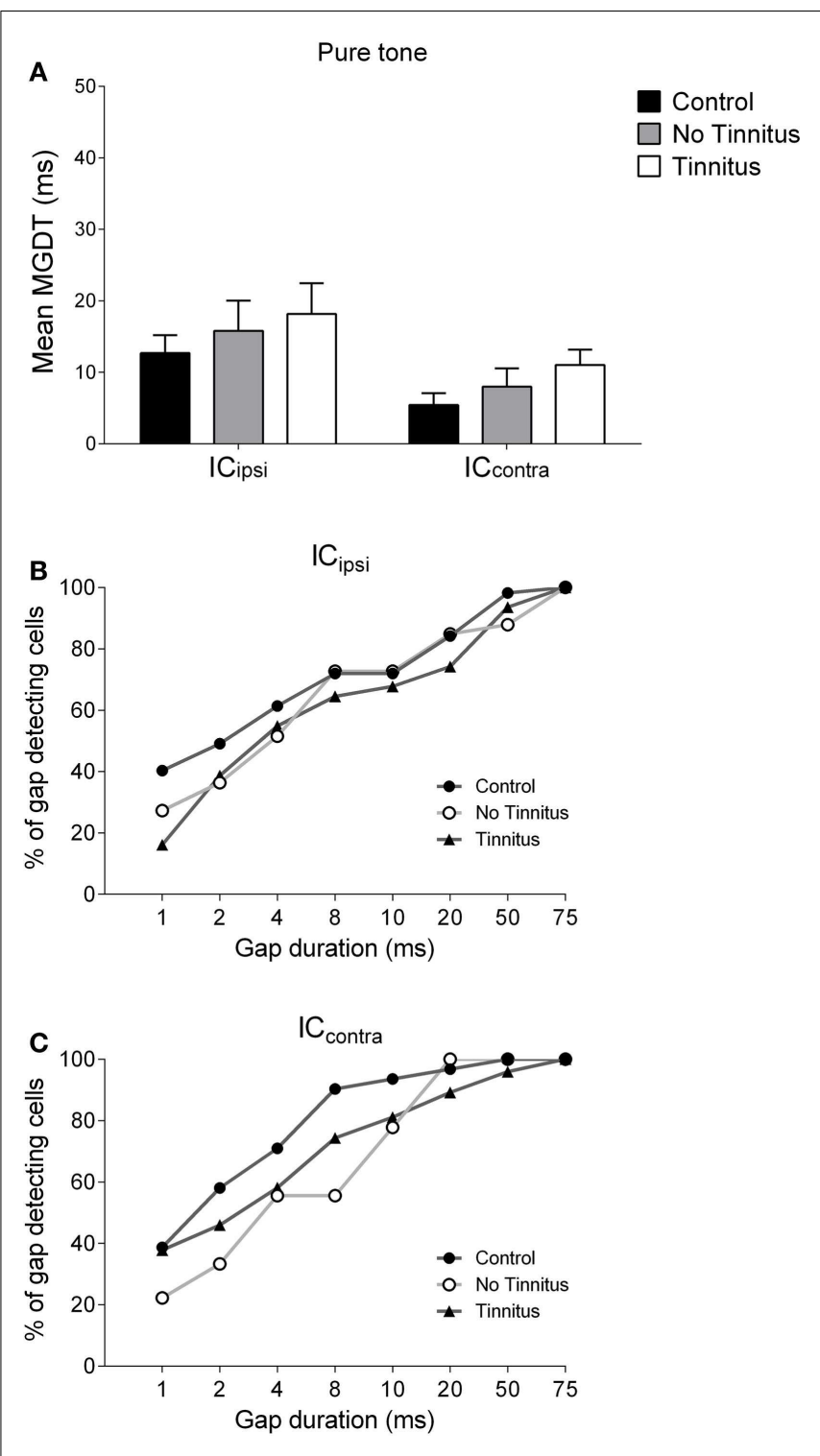

FIGURE 5 | Hemispheric differences in gap detection for pure tones. (A) Mean MGDTs in response to pure tones are shown when data were sub-divided according to recording side. The percentage of gap-detecting cells are also shown for left IC (B) and right IC (C) in response to pure tones.

Figure 5A shows mean MGDTs $( \pm \mathrm{SEM})$ in response to pure tones for control, no tinnitus, and tinnitus GPs, separated for $\mathrm{IC}_{\mathrm{ipsi}}$ and $\mathrm{IC}_{\text {contra }}$. The percentage of gap-detecting cells in $\mathrm{IC}_{\mathrm{ipsi}}$ and $\mathrm{IC}_{\text {contra }}$ are shown in Figures 5B,C, respectively. Observationally, the $\mathrm{IC}_{\text {contra }}$ exhibited shorter MGDTs than the $\mathrm{IC}_{\mathrm{ipsi}}$ in controls, no tinnitus, and tinnitus groups, indicating a rightside dominant asymmetry. Statistical analysis revealed a significantly shorter MGDT overall in the $\mathrm{IC}_{\text {contra }}$ compared with the $\mathrm{IC}_{\text {ipsi }}\left[F_{(1,229)}=5.72 ; P<0.05\right]$, but no significant effect of experimental group $\left[F_{(2,229)}=1.07, P=0.35\right]$, and no collicular side $\times$ group interaction $\left[F_{(2,229)}=0.004, P=0.99\right]$. Post hoc analyses, comparing sub-divided $\mathrm{IC}_{\mathrm{ipsi}}$ control $(n=57), \mathrm{IC}_{\mathrm{contra}}$ 

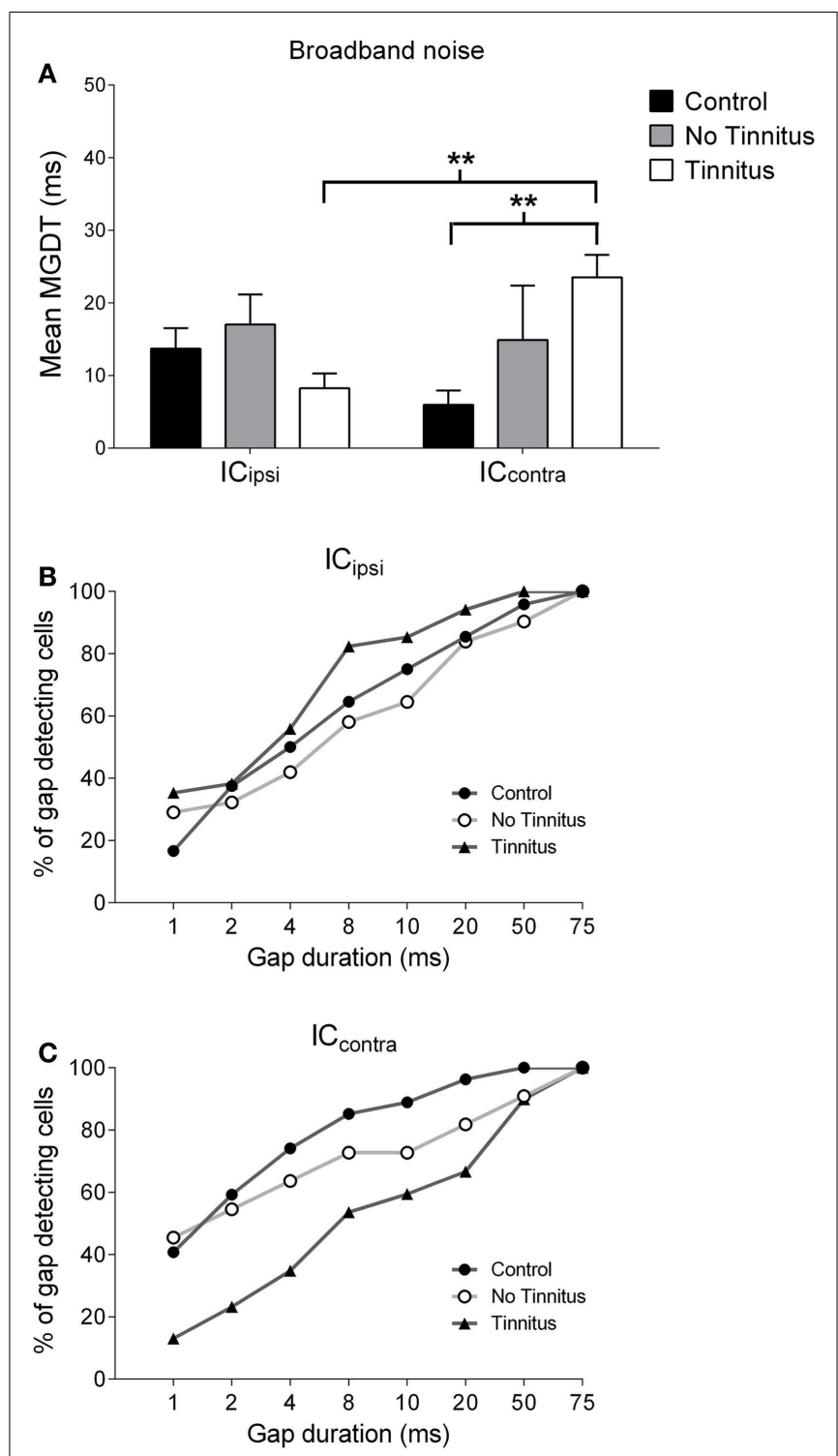

FIGURE 6 | Hemispheric differences in gap detection for BBN. (A) Mean MGDTs with a BBN carrier from control, no tinnitus, and tinnitus animals, sub-divided according to recording side $\left({ }^{*} P<0.01\right)$. The percentage of gap-detecting cells for left IC (B) and right IC (C) are also shown.

control $(n=31), \mathrm{IC}_{\mathrm{ipsi}}$ no tinnitus $(n=33), \mathrm{IC}_{\text {contra }}$ no tinnitus $(n=9), \mathrm{IC}_{\text {ipsi }}$ tinnitus $(n=31)$, and $\mathrm{IC}_{\text {contra }}$ tinnitus $(n=74)$ recordings, revealed no further differences either as a "withingroup" comparison (i.e., $\mathrm{IC}_{\mathrm{ipsi}}$ vs. $\mathrm{IC}_{\text {contra }}$ ) or "between-group" comparison (e.g., control $\mathrm{IC}_{\mathrm{ipsi}}$ vs. tinnitus $\mathrm{IC}_{\mathrm{ipsi}}$ ). The percentage of cells with MGDTs of $\leq 50 \mathrm{~ms}$ were $98 \%\left(\mathrm{IC}_{\mathrm{ipsi}}\right)$ and $100 \%$ $\left(\mathrm{IC}_{\text {contra }}\right)$ for control GPs, while for tinnitus GPs these numbers were slightly lower at $94 \%\left(\mathrm{IC}_{\mathrm{ipsi}}\right)$ and $96 \%\left(\mathrm{IC}_{\text {contra }}\right)$. In no tinnitus GPs, these numbers were lower for the $\mathrm{IC}_{\mathrm{ipsi}}(88 \%)$ and the same as controls for the $\mathrm{IC}_{\text {contra }}(100 \%)$.

Figures $\mathbf{6 A - C}$ show mean MGDTs and the percentage of gap-detecting cells in response to a BBN stimulus, separated according to side, for control, no tinnitus, and tinnitus GPs.
Overall, there were no significant differences between the two sides $\left[F_{(1,223)}=0.30 ; P=0.58\right]$, nor across experimental groups $\left[F_{(2,223)}=1.52 ; P=0.22\right]$, but a group $\times$ side interaction was present $\left[F_{(2,223)}=4.43 ; P<0.05\right]$. Post hoc analyses indicated that the $\mathrm{IC}_{\text {contra }}$ in tinnitus GPs $(n=74)$ had significantly longer MGDTs than both the $\mathrm{IC}_{\mathrm{ipsi}}$ in tinnitus GPs (the "within-group" comparison; $n=34, P<0.01)$ and the $\mathrm{IC}_{\text {contra }}$ in control GPs (the "between-group" comparison; $n=31, P<0.01$ ). Thus, neural GDTs to BBN stimuli were significantly worse in $\mathrm{IC}_{\text {contra }}$ of tinnitus GPs, which reflects activity generated by the AOE-treated ear. In response to $\mathrm{BBN}$, the percentage of cells with MGDTs of $50 \mathrm{~ms}$ or less was $96 \%\left(\mathrm{IC}_{\mathrm{ipsi}}\right)$ and $100 \%\left(\mathrm{IC}_{\text {contra }}\right)$ for control GPs. For tinnitus GPs, the percentage of units with thresholds of $\leq 50 \mathrm{~ms}$ was higher than controls for the $\mathrm{IC}_{\mathrm{ipsi}}(100 \%)$ but lower for the $\mathrm{IC}_{\text {contra }}(90 \%)$. This contrasts with responses to pure tone stimuli, i.e., no change in the trend toward right-side-dominance, simply a small increase in MGDT relative to controls. For no tinnitus GPs, the percentage of units with thresholds of $\leq 50$ ms was $90 \%$ $\left(\mathrm{IC}_{\mathrm{ipsi}}\right)$ and $91 \%\left(\mathrm{IC}_{\text {contra }}\right)$, but the small sample sizes in this group (relative to control and tinnitus GPs) should be noted.

\section{NEURAL GAP DETECTION IN ONSET AND SUSTAINED-RESPONSE SINGLE-UNITS}

Next, onset and sustained units were compared to establish whether the changes in neural gap detection were more pronounced in either of these sub-classes. Across the three experimental groups (pooled across both recording sides), in response to the pure tone stimulus, onset cells displayed a mean $( \pm$ SEM $)$ MGDT of $15.74 \mathrm{~ms}( \pm 2.16 \mathrm{~ms} ; n=103)$. The mean MGDT for sustained units was considerably shorter at $7.45 \mathrm{~ms}( \pm 1.43 \mathrm{~ms}$; $n=126)$. Offset units were excluded from analysis due to their low incidence in the sample ( $n=6$ across both groups), although the mean MGDT of offset units was considerably longer at $30.5 \mathrm{~ms}$ $( \pm 10.81 \mathrm{~ms} ; n=6)$, this is consistent with the results of other previous studies $(16,41)$.

Data were also examined to see whether MGDTs (in response to pure tones, as this was the largest sample available) varied as a function of response type for each experimental group (Figure 7): the mean $( \pm$ SEM) MGDT in control GPs for onset units was $17.43 \mathrm{~ms}( \pm 4.19 \mathrm{~ms} ; n=23)$, while sustained units had a mean MGDT of $6.75 \mathrm{~ms}( \pm 1.85 \mathrm{~ms} ; n=56)$. In no tinnitus GPs, mean MDGTs were $18.54 \mathrm{~ms}( \pm 4.55 \mathrm{~ms} ; n=26)$ for onset units and $6.94 \mathrm{~ms}( \pm 4.56 \mathrm{~ms} ; n=16)$ for sustained units. Mean MDGTs in tinnitus GPs were $13.62 \mathrm{~ms}( \pm 2.66 \mathrm{~ms} ; n=53)$ for onset units and $8.76 \mathrm{~ms}( \pm 2.42 \mathrm{~ms} ; n=50)$ for sustained units.

Statistical analysis indicated a significant overall effect of response type on MGDT $\left[F_{(1,218)}=11.15, P<0.01\right]$. However, there were no significant differences between experimental groups $\left[F_{(2,218)}=0.11, P=0.90\right]$, nor was there an interaction between experimental group and response type $\left[F_{(2,218)}=0.61 ; P=0.55\right]$ or any post hoc differences. In other words, sustained units had significantly shorter MGDTs than onset units, irrespective of experimental group.

\section{DISCUSSION}

The present study examined the effects of AOE, and the subsequent development of tinnitus, on neural gap detection in the IC. 


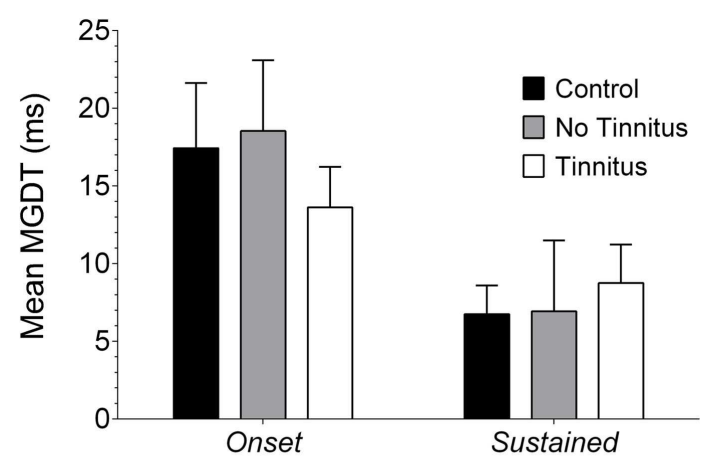

Type of response

FIGURE 7 | Neural GDTs in the different types of IC neurons. Mean MGDTs are shown for onset and sustained units (offset units were excluded owing to a small sample size) in control, no tinnitus, and tinnitus GPs.

Behavioral evidence of tinnitus was demonstrated in 75\% of animals 7-8 weeks after AOE by showing a significant reduction in their ability to detect a $50 \mathrm{~ms}$ gap. There was a notable shift in the single-unit response types in the $\mathrm{IC}_{\text {contra }}$ (reflecting a left-side unilateral exposure) of tinnitus GPs, with proportionally more units classified as onset-responders, compared with control GPs. In no tinnitus GPs, a similar shift in response types was observed in both the $\mathrm{IC}_{\mathrm{ipsi}}$ and the $\mathrm{IC}_{\text {contra }}$, although the sample sizes in this experimental group were relatively small. While some significant increases in neural GDTs were found in animals with tinnitus, it was clear that a $50 \mathrm{~ms}$ gap was detectable by the majority of IC neurons, regardless of whether or not a GP was subjected to AOE. Also, the distribution of MGDTs indicated that a large number of neurons still responded to gaps of $1 \mathrm{~ms}$ duration in animals after AOE. Moreover, in response to pure tones, MGDTs were considerably shorter in the $\mathrm{IC}_{\text {contra }}$ (right side) compared with the $\mathrm{IC}_{\mathrm{ipsi}}$ (left side) - regardless of whether animals were noise-exposed or not - suggesting that a possible right-side advantage in temporal processing in this species.

Previously, Walton et al. (16) demonstrated that there were no significant differences in MGDTs between middle-aged mice that were genetically predisposed to develop moderate hearing loss and normal-hearing young mice. This contrasts with psychophysical evidence, showing that GDTs are significantly longer in hearingimpaired human beings when sensation levels are matched to a normal-hearing population, even at a young age (42).

The present study showed that while some deficits in neural gap detection were present following AOE, these were not evident at $50 \mathrm{~ms}$ gap duration, as used in the behavioral test. These data add to an already considerable body of evidence examining factors that affect gap detection. It is important to highlight that the estimates of MGDTs found here are considerably longer than those of Walton et al. $(16,43)$. However, in their studies, sound levels were matched to the best response of each single-unit. In the present study, in order to best model the conditions of the behavioral tinnitus test, sound levels used in the neural gap detection experiments were matched with those from the behavioral test. As a result, the levels were not necessarily optimal for each unit; hence, the estimates of MGDTs may have been longer. Furthermore, the MGDT estimates presented here are very similar to the psychophysically estimated thresholds of Fitzgibbons and Wightman (42).

Given that changes in sensitivity to a $50 \mathrm{~ms}$ gap were negligible in both our tinnitus and no tinnitus animals, as well as the fact that a similar number of units responded to gaps of very short durations compared with unexposed controls, deficits in neural gap detection ability at the level of the IC following AOE are unlikely to explain behavioral gap detection deficits. However, there is an important limitation of the present study. Since most of the animals only demonstrated deficits in behavioral gap detection at particular NBN frequencies, it is reasonable to predict that neural gap detection deficits, if they were present, would be most likely to occur in neurons that responded preferentially to these frequencies. Unfortunately, in the present study, this comparison was not possible owing to a small sample size of units with CFs falling within the NBN frequency where behavioral gap detection deficits occurred. This was a result of the recording procedure which, by starting in dorsal IC, skewed our data toward low frequencies. Consequently, future experiments should examine neural GDTs primarily at frequencies where behavioral gap detection deficits are present, as this would provide further insight into the underlying mechanisms of such deficits. Furthermore, it would be of considerable benefit to determine whether any gap detection deficits were evident in the auditory cortex.

Due to the nature of our stimuli, i.e., RMS sound levels for pure tone, NBN, and BBN were the same, it is likely that a reduction in the signal energy at the CF of a neuron would cause the sound level of the BBN stimulus to be lower at a given frequency by a considerable margin, relative to pure tone stimuli of the same frequency. Small AOE-related effects on neural GDTs in tinnitus animals were restricted to the $\mathrm{IC}_{\text {contra }}$ in response to $\mathrm{BBN}$ stimuli. Thus, it is conceivable that mild residual hearing loss in tinnitus animals may have further exacerbated this reduction in perceived sound level, thereby resulting in the observed significant difference between controls and tinnitus groups only in response to BBN stimuli. Nevertheless, it should be noted that - in the same neurons - gap detection in response to pure tones remained largely intact. Furthermore, $50 \mathrm{~ms}$ gaps were detectable by the majority of IC neurons, regardless of the stimulus presented, and gaps of $1 \mathrm{~ms}$ duration were still detectable by a similar number of neurons in controls, no tinnitus, and tinnitus GPs.

Another limitation of the present study was that a number of units either did not respond strongly to any of the frequencies in the NBN condition or their CFs were not within $1 \mathrm{kHz}$ of the frequency range of the NBN, hence an MGDT could not be reliably obtained. Consequently, the sample size for this condition is substantially lower than pure tone or BBN conditions. Nonetheless, the average MGDT for units that were responsive to NBN was considerably $<50 \mathrm{~ms}$ gap duration of the behavioral test. Furthermore, it has previously been shown that psychophysical GDTs may feasibly be determined by across-channel integration of responsive neurons (44). Given that pure tones (at the CF of a cell) generate the most robust sound-evoked response, it can be assumed that the mean MGDT to the pure tone gap condition is a reasonable predictor of behavioral GDTs. The fact that pure tone responses had, 
on average, similar MGDTs in tinnitus, no tinnitus, and control animals, suggests that gross deficits in neural gap detection were not responsible for the behavioral gap detection deficits observed in the same animals.

It is also important to note that gaps of different durations are employed by other researchers demonstrating behavioral gap detection deficits, including $75 \mathrm{~ms}$ (45), $40 \mathrm{~ms}$ (34), $20 \mathrm{~ms}$ (11), and $15 \mathrm{~ms}(10,26)$. However, in the present study, a similar percentage of neurons had MGDTs of $\leq 10 \mathrm{~ms}$ in response to pure tones in tinnitus GPs, compared with controls and no tinnitus GPs (80 vs. 77 and $74 \%$, respectively). Furthermore, a large number of units were still able to respond to gaps of $1 \mathrm{~ms}$ duration following AOE. Therefore, it is unlikely that temporal processing deficits following AOE were causing behavioral gap detection deficits, even in studies employing gaps of shorter durations.

Fournier and Hebert (14) suggested that tinnitus may not be filling in the gap per se, as the deficits in gap detection they observed in patients with high-frequency tinnitus (by measuring the eyeblink reflex) were not limited to a high-frequency background carrier, but were also present in a low-frequency carrier condition. However, the frequency most similar to patients' tinnitus $(16 \mathrm{kHz})$, as determined using a likeness-matching procedure [e.g., Ref. (46)], was not matched to the frequency of the background carrier $(4 \mathrm{kHz}$ for the high-frequency condition; $500 \mathrm{~Hz}$ for the low-frequency condition). Consequently, it would have been of significant interest to determine whether gap detection deficits were augmented at the tinnitus frequency compared with the other frequencies tested. Contrary to the results of Fournier and Hebert (14); Campolo et al. (47) demonstrated that people with tinnitus were still capable of psychophysical gap detection when the gap background carrier was matched to tinnitus frequency. It is possible, however, that fundamental differences in the paradigms (e.g., using a reflex response compared with a cognitive task) may explain these seemingly contradictory results. Further studies are needed that use carrier frequencies more similar to the characteristics of patients' tinnitus, as well as comparing the two different tasks (reflexive and cognitive), in order to determine whether the hypothesis of "filling in" the gap is applicable to human beings.

In the present study, we did not measure the spontaneous firing rates of IC neurons. Although elevated spontaneous firing has previously been demonstrated following AOE [e.g., Ref. $(18,19)]$, we recently established that this was not solely indicative of tinnitus in our model owing to the fact that elevated spontaneous firing was also present in AOE-treated animals with no behavioral evidence of tinnitus (8). Nevertheless, it is plausible that increased spontaneous firing at a cortical or subcortical level could render the gap undetectable, thus, causing a reduction in temporal acuity, an idea proposed previously (48). If this was indeed the cause of impaired behavioral gap detection, it would be anticipated that gap detection is significantly impaired in IC neurons. Given that only slight changes in neural GDTs were observed in tinnitus animals compared with both unexposed controls and no tinnitus GPs, it therefore seems unlikely that elevated spontaneous firing at the level of the IC is the direct cause of impaired behavioral gap detection. However, increased spontaneous activity at the level of the auditory cortex cannot be discounted as a contributing factor to impaired behavioral performance.
A right-side advantage in temporal processing was identified for unexposed controls, no tinnitus GPs, and tinnitus GPs in response to pure tones, i.e., mean MGDTs in $\mathrm{IC}_{\mathrm{ipsi}}$ were considerably longer than $\mathrm{IC}_{\text {contra }}$. However, the sample sizes in these data were relatively small and definitive conclusions cannot therefore be drawn. In human beings, some psychophysical studies have previously reported that a left hemisphere advantage was evident in temporal processing [e.g., Ref. $(49,50)$ ], contrasting with the rightside advantage demonstrated here. However, other psychophysical studies failed to reproduce this left hemisphere advantage in human beings [e.g., Ref. $(51,52)]$. Nonetheless, the data presented here conflict with human psychophysical literature reporting a left-side advantage. Furthermore, Wetzel et al. (53) found that, in gerbils, the detection of gaps in frequency-modulated tones in a behavioral task was impaired by left, but not right, auditory cortex lesions, suggesting hemispheric differences in temporal processing in this species. It is highly plausible that differences between these studies and the paradigm used here may play a role in any inconsistencies in these findings (e.g., species differences, the use of anesthetics, or procedural differences, i.e., electrophysiology vs. psychophysics). Interestingly, fMRI studies in human beings support the findings of a right-side advantage and contradict the human psychophysical results, demonstrating increased activation in the right hemisphere that was better-correlated with performance on a temporal processing task than was the case for the left hemisphere $(54,55)$. Further investigation of hemispheric temporal processing differences in animals is necessary to address these discrepancies in the literature.

It was particularly intriguing that there was a significant increase in the proportion of units exhibiting onset responses following AOE. The proportion of onset/sustained responses in control animals shown here was very similar to that reported previously for urethane-anesthetized GPs [21\% onset vs. $73 \%$ sustained; (56)]. Changes in response types of units recorded in the IC have previously been demonstrated following bicuculline and strychnine administration (56). For example, $~ 50 \%$ of units demonstrated changes in PSTHs following application of either drug, most commonly transforming into "chopper" responses, characterized by a regular discharge pattern of three or more peaks near the stimulus onset, regardless of the previous unit response classification. These changes in response type were attributed to the antagonistic effect that these drugs have on GABA and glycine receptors. As an added confound, the class of anesthetic can affect the proportion of different temporal response types, the percentage of onset units recorded in the IC of control GPs was significantly greater under pentobarbital anesthesia than ketamine or urethane (31). In contrast to the data presented here, studies in the GP (57) and the chinchilla (58) showed no marked change in the types of single-unit responses in the IC after AOE. However, these findings related to recordings performed immediately after acute noise exposure, whereas the data presented here provide the first evidence for long-term changes in response types following AOE.

There is evidence indicating that IC units with different types of responses may have different functional roles. For example, Zheng and Escabi (59) demonstrated that sustained units are effective at encoding the envelope shape of stimuli with low-modulation rates, while onset units are most suited to representing repetitive 
stimuli at high-modulation rates. The response properties of IC units are largely determined by inhibitory inputs (56), mediated by GABA and glycine inhibitory neurotransmitters. Wallace et al. (60) suggested that onset responses were likely to come from multipolar cells rather than from laminar cells in the IC, while sustained units were recorded from both flat laminar cells and multipolar cells, highlighting possible morphological differences underlying the two response types. It seems unlikely that AOE would cause a complete change in morphological class, i.e., from laminar to multipolar cell, to account for the change in the proportion of onset neurons. However, multipolar cells previously exhibiting sustained responses could be altered to produce onset responses. As yet, it is unclear how this change may be caused by AOE. Changes in the balance of excitation and inhibition, as observed following acoustic trauma and linked to tinnitus (61-63), could possibly contribute to the changes in the response patterns of units observed here. However, given that inhibitory antagonists (such as bicuculline or strychnine) increased the discharge rate of neurons in the IC (56), the shift toward a higher proportion of onset cells following AOE observed here, wherein inhibition is likely to be reduced [for a review, see Ref. (64)], appears to be counterintuitive.

At present, given the current evidence, a gross change in neural GDTs within the IC is unlikely to be the basis of behavioral gap detection deficits. Furthermore, the original perceptual "filling in" hypothesis presented by Turner et al. (6) presumably involves the forebrain $(65,66)$. Previous work in rats established that auditory cortex ablation increased behavioral GDTs (67); thus, the auditory cortex may be a candidate for involvement in the increased neural thresholds shown here. The auditory cortex has a profound effect on temporal processing in the IC (68), and it is possible that corticofugal modulation might be central in changing the proportion of onset cells in the IC. Further research relating changes in response types to tinnitus may prove useful in elucidating the mechanisms by which the IC contributes to the generation of the tinnitus percept.

\section{ACKNOWLEDGMENTS}

Ben Coomber was supported in part by Action on Hearing Loss (International Project Grant G62). The authors wish to thank Trevor M. Shackleton for assistance in developing sound stimuli, and Lucy A. Anderson and Jennifer F. Linden for helpful advice in devising a paradigm for measuring neural gap detection. The authors declare no competing financial interests.

\section{REFERENCES}

1. Baguley D, Mcferran D, Hall D. Tinnitus. Lancet (2013) 382:1600-7. doi:10. 1016/S0140-6736(13)60142-7

2. Langguth B, Kreuzer PM, Kleinjung T, De Ridder D. Tinnitus: causes and clinical management. Lancet Neurol (2013) 12:920-30. doi:10.1016/S1474-4422(13) 70160-1

3. Bauer CA, Brozoski TJ. Assessing tinnitus and prospective tinnitus therapeutics using a psychophysical animal model. J Assoc Res Otolaryngol (2001) 2:54-64. doi:10.1007/s101620010030

4. Heffner HE, Harrington IA. Tinnitus in hamsters following exposure to intense sound. Hear Res (2002) 170:83-95. doi:10.1016/S0378-5955(02)00343-X

5. Jastreboff PJ, Brennan JF, Coleman JK, Sasaki CT. Phantom auditory sensation in rats: an animal model for tinnitus. Behav Neurosci (1988) 102:811-22. doi:10.1037/0735-7044.102.6.811
6. Turner JG, Brozoski TJ, Bauer CA, Parrish JL, Myers K, Hughes LF, et al. Gap detection deficits in rats with tinnitus: a potential novel screening tool. Behav Neurosci (2006) 120:188-95. doi:10.1037/0735-7044.120.1.188

7. Berger JI, Coomber B, Shackleton TM, Palmer AR, Wallace MN. A novel behavioural approach to detecting tinnitus in the guinea pig. JNeurosci Methods (2013) 213:188-95. doi:10.1016/j.jneumeth.2012.12.023

8. Coomber B, Berger JI, Kowalkowski VL, Shackleton TM, Palmer AR, Wallace MN. Neural changes accompanying tinnitus following unilateral acoustic trauma in the guinea pig. Eur J Neurosci (2014) 40(2):2427-41. doi:10.1111/ejn. 12580

9. Chen G, Lee C, Sandridge SA, Butler HM, Manzoor NF, Kaltenbach JA. Behavioral evidence for possible simultaneous induction of hyperacusis and tinnitus following intense sound exposure. J Assoc Res Otolaryngol (2013) 14:413-24. doi:10.1007/s10162-013-0375-2

10. Dehmel S, Eisinger D, Shore SE. Gap prepulse inhibition and auditory brainstem-evoked potentials as objective measures for tinnitus in guinea pigs. Front Syst Neurosci (2012) 6:42. doi:10.3389/fnsys.2012.00042

11. Longenecker RJ, Galazyuk AV. Development of tinnitus in CBA/CaJ mice following sound exposure. J Assoc Res Otolaryngol (2011) 12:647-58. doi:10.1007/ s10162-011-0276-1

12. Turner JG, Parrish J. Gap detection methods for assessing salicylate-induced tinnitus and hyperacusis in rats. Am J Audiol (2008) 17:S185-92. doi:10.1044/ 1059-0889(2008/08-0006)

13. Turner J, Larsen D, Hughes L, Moechars D, Shore S. Time course of tinnitus development following noise exposure in mice. J Neurosci Res (2012) 90:1480-8. doi:10.1002/Jnr.22827

14. Fournier P, Hebert S. Gap detection deficits in humans with tinnitus as assessed with the acoustic startle paradigm: does tinnitus fill in the gap? Hear Res (2013) 295:16-23. doi:10.1016/j.heares.2012.05.011

15. Eggermont JJ. Neural correlates of gap detection in three auditory cortical fields in the cat. J Neurophysiol (1999) 81:2570-81.

16. Walton JP, Barsz K, Wilson WW. Sensorineural hearing loss and neural correlates of temporal acuity in the inferior colliculus of the C57BL/6 mouse. J Assoc Res Otolaryngol (2008) 9:90-101. doi:10.1007/s10162-007-0101-Z

17. Yin SK, Feng YM, Chen ZN, Wang J. The effect of noise-induced sloping highfrequency hearing loss on the gap-response in the inferior colliculus and auditory cortex of guinea pigs. Hear Res (2008) 239:126-40. doi:10.1016/j.heares. 2008.02.002

18. Bauer CA, Turner JG, Caspary DM, Myers KS, Brozoski TJ. Tinnitus and inferior colliculus activity in chinchillas related to three distinct patterns of cochlear trauma. J Neurosci Res (2008) 86:2564-78. doi:10.1002/jnr.21699

19. Mulders WH, Robertson D. Hyperactivity in the auditory midbrain after acoustic trauma: dependence on cochlear activity. Neuroscience (2009) 164:733-46. doi:10.1016/j.neuroscience.2009.08.036

20. Mulders WH, Robertson D. Progressive centralization of midbrain hyperactivity after acoustic trauma. Neuroscience (2011) 192:753-60. doi:10.1016/j. neuroscience.2011.06.046

21. Wang F, Zuo L, Hong B, Han D, Range EM, Zhao L, et al. Tonotopic reorganization and spontaneous firing in inferior colliculus during both short and long recovery periods after noise overexposure. J Biomed Sci (2013) 20:91. doi:10.1186/1423-0127-20-91

22. Irvine DR, Rajan R, Smith S. Effects of restricted cochlear lesions in adult cats on the frequency organization of the inferior colliculus. J Comp Neurol (2003) 467(3):354-74. doi:10.1002/cne.10921

23. Wang H, Brozoski TJ, Caspary DM. Inhibitory neurotransmission in animal models of tinnitus: maladaptive plasticity. Hear Res (2011) 279:111-7. doi:10.1016/j.heares.2011.04.004

24. Walton JP, Frisina RD, Ison JR, O'Neill WE. Neural correlates of behavioral gap detection in the inferior colliculus of the young CBA mouse. J Comp Physiol A (1997) 181:161-76. doi:10.1007/s003590050103

25. Casseday JH, Fremouw T, Covey E. The inferior colliculus: a hub for the central auditory system. In: Oertel D, Fay RR, Popper AN, editors. Integrative Functions in the Mammalian Auditory Pathway. New York, NY: Springer (2002). p. 238-318.

26. Dehmel S, Pradhan S, Koehler S, Bledsoe S, Shore S. Noise overexposure alters long-term somatosensory-auditory processing in the dorsal cochlear nucleus possible basis for tinnitus-related hyperactivity? J Neurosci (2012) 32:1660-71. doi:10.1523/JNEUROSCI.4608-11.2012 
27. Zhang J, Zhang Y, Zhang X. Auditory cortex electrical stimulation suppresses tinnitus in rats. JAssoc Res Otolaryngol (2011) 12:185-201. doi:10.1007/s10162010-0246-z

28. Rapisarda C, Bacchelli B. The brain of the guinea pig in stereotaxic coordinates. Arch Sci Biol (1977) 61:1.

29. Malmierca MS, Rees A, Le Beau FE, Bjaalie JG. Laminar organization of frequency-defined local axons within and between the inferior colliculi of the guinea pig. J Comp Neurol (1995) 357:124-44. doi:10.1002/cne.903570112

30. Bullock DC, Palmer AR, Rees A. Compact and easy-to-use tungsten-in-glass microelectrode manufacturing workstation. Med Biol Eng Comput (1988) 26:669-72. doi:10.1007/BF02447511

31. Astl J, Popelar J, Kvasnak E, Syka J. Comparison of response properties of neurons in the inferior colliculus of guinea pigs under different anesthetics. Audiology (1996) 35:335-45. doi:10.3109/00206099609071954

32. Kasai M, Ono M, Ohmori H. Distinct neural firing mechanisms to tonal stimuli offset in the inferior colliculus of mice in vivo. Neurosci Res (2012) 73:224-37. doi:10.1016/j.neures.2012.04.009

33. Nowotny M, Remus M, Kossl M, Gaese BH. Characterization of the perceived sound of trauma-induced tinnitus in gerbils. J Acoust Soc Am (2011) 130:2827-34. doi:10.1121/1.3646902

34. Pace E, Zhang J. Noise-induced tinnitus using individualized gap detection analysis and its relationship with hyperacusis, anxiety, and spatial cognition. PLoS One (2013) 8:e75011. doi:10.1371/journal.pone.0075011

35. Kraus KS, Mitra S, Jimenez Z, Hinduja S, Ding D, Jiang H, et al. Noise trauma impairs neurogenesis in the rat hippocampus. Neuroscience (2010) 167:1216-26. doi:10.1016/j.neuroscience.2010.02.071

36. Engineer ND, Riley JR, Seale JD, Vrana WA, Shetake JA, Sudanagunta SP, et al. Reversing pathological neural activity using targeted plasticity. Nature (2011) 470:101-U114. doi:10.1038/Nature09656

37. Penner MJ. Variability in matches to subjective tinnitus. J Speech Hear Res (1983) 26:263-7. doi:10.1044/jshr.2602.263

38. Tyler RS, Conrad-Armes D. Tinnitus pitch: a comparison of three measurement methods. Br J Audiol (1983) 17:101-7. doi:10.3109/03005368309078916

39. Burns EM. A comparison of variability among measurements of subjective tinnitus and objective stimuli. Audiology (1984) 23:426-40. doi:10.3109/ 00206098409081535

40. Henry JA, Flick CL, Gilbert A, Ellingson RM, Fausti SA. Comparison of manual and computer-automated procedures for tinnitus pitch-matching. J Rehabil Res Dev (2004) 41:121-38. doi:10.1682/JRRD.2004.02.0121

41. Wilson WW, Walton JP. Background noise improves gap detection in tonically inhibited inferior colliculus neurons. J Neurophysiol (2002) 87:240-9.

42. Fitzgibbons PJ, Wightman FL. Gap detection in normal and hearing-impaired listeners. J Acoust Soc Am (1982) 72:761-5. doi:10.1121/1.388256

43. Walton JP, Frisina RD, O’Neill WE. Age-related alteration in processing of temporal sound features in the auditory midbrain of the CBA mouse. J Neurosci (1998) 18:2764-76.

44. Eggermont JJ. Neural responses in primary auditory cortex mimic psychophysical, across-frequency-channel, gap-detection thresholds. J Neurophysiol (2000) 84(3):1453-63.

45. Lobarinas E, Hayes SH, Allman BL. The gap-startle paradigm for tinnitus screening in animal models: limitations and optimization. Hear Res (2013) 295:150-60. doi:10.1016/j.heares.2012.06.001

46. Moore BCJ, Vinay, Sandhya. The relationship between tinnitus pitch and the edge frequency of the audiogram in individuals with hearing impairment and tonal tinnitus. Hear Res (2010) 261:51-6. doi:10.1016/j.heares. 2010.01.003

47. Campolo J, Lobarinas E, Salvi R. Does tinnitus "fill in" the silent gaps? Noise Health (2013) 15:398-405. doi:10.4103/1463-1741.121232

48. Eggermont JJ. Hearing loss, hyperacusis, or tinnitus: what is modeled in animal research? Hear Res (2013) 295:140-9. doi:10.1016/j.heares.2012.01.005

49. Brown S, Nicholls ME. Hemispheric asymmetries for the temporal resolution of brief auditory stimuli. Percept Psychophys (1997) 59:442-7. doi:10.5935/18088694.20130057

50. Sulakhe N, Elias LJ, Lejbak L. Hemispheric asymmetries for gap detection depend on noise type. Brain $\operatorname{Cogn}$ (2003) 53:372-5. doi:10.1016/S0278-2626(03) 00146-5

51. Efron R, Yund EW, Nichols D, Crandall PH. An ear asymmetry for gap detection following anterior temporal lobectomy. Neuropsychologia (1985) 23:43-50. doi:10.1016/0028-3932(85)90042-9
52. Samelli AG, Schochat E. Study of the right ear advantage on gap detection tests. Braz J Otorhinolaryngol (2008) 74:235-40. doi:10.1590/S003472992008000200013

53. Wetzel W, Ohl FW, Scheich H. Global versus local processing of frequencymodulated tones in gerbils: an animal model of lateralized auditory cortex functions. Proc Natl Acad Sci US A (2008) 105:6753-8. doi:10.1073/pnas.0707844105

54. Harrington DL, Boyd LA, Mayer AR, Sheltraw DM, Lee RR, Huang M, et al. Neural representation of interval encoding and decision making. Brain Res Cogn Brain Res (2004) 21:193-205. doi:10.1016/j.cogbrainres.2004.01.010

55. Reiterer SM, Erb M, Droll CD, Anders S, Ethofer T, Grodd W, et al. Impact of task difficulty on lateralization of pitch and duration discrimination. Neuroreport (2005) 16:239-42. doi:10.1097/00001756-200502280-00007

56. Le Beau FE, Rees A, Malmierca MS. Contribution of GABA- and glycinemediated inhibition to the monaural temporal response properties of neurons in the inferior colliculus. J Neurophysiol (1996) 75:902-19.

57. Popelar J, Syka J. Noise impairment in the guinea pig. II. Changes of single unit responses in the inferior colliculus. Hear Res (1982) 8:273-83. doi:10.1016/ 0378-5955(82)90019-3

58. Wang J, Salvi RJ, Powers N. Plasticity of response properties of inferior colliculus neurons following acute cochlear damage. J Neurophysiol (1996) 75:171-83.

59. Zheng Y, Escabi MA. Distinct roles for onset and sustained activity in the neuronal code for temporal periodicity and acoustic envelope shape. J Neurosci (2008) 28:14230-44. doi:10.1523/JNEUROSCI.2882-08.2008

60. Wallace MN, Shackleton TM, Palmer AR. Morphological and physiological characteristics of laminar cells in the central nucleus of the inferior colliculus. Front Neural Circuits (2012) 6:55. doi:10.3389/fncir.2012.00055

61. Dong S, Mulders WH, Rodger J, Robertson D. Changes in neuronal activity and gene expression in guinea-pig auditory brainstem after unilateral partial hearing loss. Neuroscience (2009) 159:1164-74. doi:10.1016/j.neuroscience.2009.01. 043

62. Dong S, Mulders WH, Rodger J, Woo S, Robertson D. Acoustic trauma evokes hyperactivity and changes in gene expression in guinea-pig auditory brainstem. Eur J Neurosci (2010) 31:1616-28. doi:10.1111/j.1460-9568.2010.07183.x

63. Dong S, Rodger J, Mulders WH, Robertson D. Tonotopic changes in GABA receptor expression in guinea pig inferior colliculus after partial unilateral hearing loss. Brain Res (2010) 1342:24-32. doi:10.1016/j.brainres.2010.04.067

64. Salvi RJ, Wang J, Ding D. Auditory plasticity and hyperactivity following cochlear damage. Hear Res (2000) 147:261-74. doi:10.1016/S0378-5955(00)00136-2

65. Ison JR, O'Connor K, Bowen GP, Bocirnea A. Temporal resolution of gaps in noise by the rat is lost with functional decortication. Behav Neurosci (1991) 105:33-40. doi:10.1037/0735-7044.105.1.33

66. Kelly JB. The effects of insular and temporal lesions in cats on two types of auditory pattern discrimination. Brain Res (1973) 62:71-87. doi:10.1016/00068993(73)90620-3

67. Syka J, Rybalko N, Mazelova J, Druga R. Gap detection threshold in the rat before and after auditory cortex ablation. Hear Res (2002) 172:151-9. doi:10.1016/S0378-5955(02)00578-6

68. Nakamoto KT, Jones SJ, Palmer AR. Descending projections from auditory cortex modulate sensitivity in the midbrain to cues for spatial position. J Neurophysiol (2008) 99:2347-56. doi:10.1152/jn.01326.2007

Conflict of Interest Statement: The authors declare that the research was conducted in the absence of any commercial or financial relationships that could be construed as a potential conflict of interest.

Received: 26 June 2014; accepted: 26 September 2014; published online: 09 October 2014.

Citation: Berger JI, Coomber B, Wells TT, Wallace MN and Palmer AR (2014) Changes in the response properties of inferior colliculus neurons relating to tinnitus. Front. Neurol. 5:203. doi: 10.3389/fneur.2014.00203

This article was submitted to Neuro-otology, a section of the journal Frontiers in Neurology.

Copyright (C) 2014 Berger, Coomber, Wells, Wallace and Palmer. This is an open-access article distributed under the terms of the Creative Commons Attribution License (CC BY). The use, distribution or reproduction in other forums is permitted, provided the original author(s) or licensor are credited and that the original publication in this journal is cited, in accordance with accepted academic practice. No use, distribution or reproduction is permitted which does not comply with these terms. 